\title{
CAR AND HOME SMOKE-FREE ZONE
}

Passive smoking is breathing in other people's smoke. It affects smokers and non-smokers. The process of smoking produces three different types of tobacco smoke:

- mainstream smoke: smoke directly inhaled by the smoker through a burning cigarette, cigar or pipe;

- exhaled mainstream smoke: smoke breathed out by the smoker;

- $\quad$ sidestream smoke: smoke that drifts from the burning end of a cigarette.

Environmental tobacco smoke (ETS) is the combination of exhaled mainstream smoke and sidestream smoke. ${ }^{1}$

Sidestream smoke contains many cancer causing chemicals and other toxic substances. In some cases, their levels are 30 times higher than in the smoke inhaled by the smoker. ${ }^{2}$ For example, compared to mainstream smoke, sidestream smoke contains greater amounts of ammonia, benzene, carbon monoxide, nicotine and some carcinogens from the same amount of burnt tobacco. ${ }^{1}$ The health effects of exposure to passive smoking are well known. It increases the risk of lung cancer and heart disease as well as throat and chest infections. . $^{1,3,4}$

Children are especially vulnerable to passive smoking. Passive smoking by infants is a risk factor for Sudden

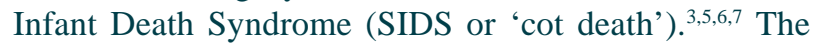
children of parents who smoke also have higher rates of lower respiratory illnesses such as croup, bronchitis, bronchiolitis and pneumonia during their first 18 months of life compared to children of non-smokers. ${ }^{3,5,6}$ Children in this age group exposed to tobacco smoke have higher rates of admission to hospital. , $^{3,9}$

Children of smokers also show a small lowering in lung function, ${ }^{5}$ with some evidence indicating that this reduced ability of lung function may even persist into adulthood. ${ }^{5}$ Children exposed to passive smoking are more likely to suffer from asthma in childhood. ${ }^{3,5,6}$

Children of smokers are more likely to contract otitis media ('glue ear'), which is an infection and swelling of the ear. ${ }^{1}$ Passive smoking increases the risk of meningococcal disease among children, which can sometimes cause death, mental disability, hearing loss, or loss of a limb. ${ }^{10}$ Exposure to tobacco smoke also makes children more vulnerable to lung complications during and after surgery involving a general anaesthetic. ${ }^{11,12}$
However, over 80 per cent of homes in NSW are now smoke-free, and most enclosed public places in NSW are by law also smoke-free. ${ }^{13}$ Bans on smoking in your home and car will not only increase your chances of quitting successfully, but others will also benefit from less exposure to passive smoking.

\section{GOING SMOKE-FREE}

Steps to make your home smoke-free are:

- get household members to agree on a date when the house becomes smoke-free;

- remove ashtrays and lighters from indoor areas;

- display no smoking stickers on the fridge and at the front door;

- ask smokers to smoke outside when they visit.

Steps to make your car smoke-free are:

- clean out the ashtray and remove the cigarette lighter;

- display 'no smoking' stickers on the dashboard or ashtray.

It is important to remember that strategies such as smoking in only one part of the house or blowing smoke out an open car window are not effective. There are invisible gases in tobacco smoke that spread quickly to all areas of the house and car. See the fact sheet Nicotine and other poisons for more information. To avoid exposure, make your car and home smoke-free.

\section{HOUSEHOLD MEMBERS}

By obtaining agreement from everybody in the house, you can avoid disputes. It is important to consider:

- where smoking is permitted outside the house: for example, on the balcony, in the garage, etc.;

- how smokers will be reminded if they forget about the smoke free zones: for example, a firm but polite reminder is usually sufficient.

\section{VISITORS}

As 80 per cent of NSW homes are smoke-free, a ban on smoking inside your house and car should be acceptable to most visitors. Clear communication is essential. Try:

- displaying 'no smoking' signs in your car and home; 
- explaining to your visitors why your car and home are smoke-free;

- setting a good example by refusing to smoke in the cars and homes of your friends and family.

\section{SMOKE-FREE STICKERS}

Smoke-free stickers that say 'Car and Home Smoke-free Zone' are available from the Better Health Centre by phone at (02) 9879 0443. Further information is available from the Car and Home Smoke-free Zone website at www.smokefreezone.org.

\section{REFERENCES}

1. US Department of Health and Human Services. The Health Consequences of Involuntary Smoking. A report of the Surgeon-General. Rockville, Maryland: US Department of Health and Human Services, Public Health Service, Centers for Disease Control, Center for Health Promotion and Education, Office on Smoking and Health, 1986.

2. Armstrong BK. Commentary: Passive smoking and lung cancer. Smoking and Public Health. Commun Health Stud 1987; 11(S-1): s6-s8.

3. National Health and Medical Research Council. The health effects of passive smoking: A Scientific Information Paper, 1997, at www.nhmrc.gov.au/advice/nhmrc/execsum.htm.
4. Commonwealth of Australia. Environmental Tobacco Smoke in Australia. National Tobacco Strategy 1999 to 2002-03 Occasional Paper. Canberra: Commonwealth Department of Health and Ageing, 2002.

5. National Cancer Institute. Health effects of exposure to environmental tobacco smoke: A report of the California Environmental Protection Agency. Smoking and Tobacco Control Monograph no. 10. NIH Publication no. 99-4645. Bethesda, MD: US Department of Health and Human Services, National Institutes of Health, National Cancer Institute, 1999.

6. World Health Organization. International Consultation on Environmental Tobacco Smoke (ETS) and Child Health. 1114 January 1999. Geneva: World Health Organization, Division of Non-communicable Diseases, 1999.

7. Ridolfo B, Stevenson C. The quantification of drug-caused mortality and morbidity in Australia, 1998. Drug Statistics Series no. 7. Canberra: Australian Institute of Health and Welfare, 2001.

8. Lam TH, Leung GM, Ho LM. The effects of environmental tobacco smoke on health services utilization in the first eighteen months of life. Pediatrics 2001; 107(6): E91.

9. Chen Y. Environmental tobacco smoke, low birthweight, and hospitalization for respiratory disease. Am J Respir Crit Care Med 1994; 150(1): 54-8.

10. Rosenstein NE, Perkins BA, Stephens DS, Popovic T, Hughes JM. Meningococcal disease [Review]. N Engl J Med. 2001; 344(18): 1378-88. 稓

This fact sheet is one of a series on tobacco and health related issues produced by the Tobacco and Health Branch of the NSW Department of Health. The fact sheets respond to frequently asked questions and are designed to be used by both consumers and health professionals to help people to quit smoking.

The fact sheets can be accessed through the NSW Department of Health's website at www.health.nsw.gov.au/public-health/health-promotion/tobacco/facts/index.html.

\section{NSW(Y)}

